\title{
A CONSTRUÇÃO DO CURRÍCULO EM SALA DE AULA: DESAFIOS E POSSIBILIDADES
}

\section{CURRICULUM CONSTRUCTION IN THE CLASSROOM: CHALLENGES AND POSSIBILITIES}

\author{
Helena Maria dos Santos FELÍCIO* \\ Ronaldo Alexandre de OLIVEIRA**
}

Resumo: Este trabalho pretende socializar e discutir os resultados de uma pesquisa que objetiva analisar o processo de construção do currículo em sala de aula, ou seja, do currículo em ação e refletir sobre ele. Na análise, buscamos identificar e compreender os desafios e possibilidades de tal construção curricular, tanto no processo de formação inicial de professores, como na formação contínua do professor de Ensino Superior. Esta possibilidade construtiva nos leva ao encontro da compreensão de que professor e alunos são sujeitos no processo de ensino e aprendizagem quando, efetivamente, ambos são envolvidos na arquitetura das ações curriculares, favorecendo, continuamente, o exercício da auto-formação. Partindo do pressuposto que a sala de aula é um espaço fundamental e necessário às relações pessoais e cognitivas, destacamos a possibilidade de construir um currículo em uma perspectiva horizontal, ou seja, em um processo dialógico permanente, rompendo com a lógica da hierarquização do conhecimento e com as relações autoritárias de poder. Sustentados, teoricamente, nas proposições de Alves (2002), Freire (1987, 1997, 2000), Giroux (2001), Hadji (2001) e Saul (2000), analisamos os dados provenientes de uma experiência desenvolvida durante o segundo semestre de 2004, na disciplina de Didática, ministrada no quarto período do Curso Normal Superior, da Universidade do Vale do Paraíba (Univap), onde constatamos a possibilidade de construir o currículo em sala de aula com indícios de autonomia e emancipação, uma vez que nessa experiência foi possível democratizar a relação professor-aluno, bem como as ações curriculares no desenvolvimento do curso.

Palavras-chave: Construção de currículo. Formação de professores. Docência.

Abstract: The aim of this article is to share and discuss the findings of a research which intends to analyze the process of curriculum construction in the classroom, that

\footnotetext{
* Mestre em Educação: Currículo (PUC/SP). Professora na Universidade do Vale do Paraíba

- Univap. helenasts@ directnet.com.br

** Doutor em Educação: Currículo (PUC/SP). Professor na Universidade do Vale do Paraíba

- Univap. roliv1@uol.com.br 
is, the curriculum in action and to reflect on this process. In the analysis the intention was to identify and comprehend the challenges and possibilities of such construction in initial teacher education as well as in the continuing education of undergraduate level professors. This possibility of construction allows the comprehension of the fact that both teachers and students are subjects of the teaching-learning process when they are effectively involved in the development of the curricular actions, which continuously favors self-education. Bearing in mind the assumption that the classroom is an essential and necessary space for personal and cognitive relations, it is emphasized the possibility of constructing the curriculum in a horizontal perspective, that is, in a permanent dialogical process that breaks the logic of hierarchization of knowledge and the power relations. The theoretical framework for the analysis was based on the propositions of Alves (2002), Freire (1987, 1997, 2000), Giroux (2001), Hadji (2001) and Saul (2000). The data analyzed was obtained from an experience developed during the second semester of 2004 at the Didactics course of the $4^{\text {th }}$ period of the Initial Teacher Training - Primary Education, from the Universidade do Vale do Paraíba (Univap). The analysis suggested the possibility of constructing the curriculum in the classroom indicating autonomy and emancipation, as in this experience it was possible to have a democratic relationship between teacher and students, as well as curricular actions in the development of the course.

Keywords: Curriculum Construction. Teacher Education. Teaching.

A construção do currículo em sala de aula é, por um lado, um desafio proposto a todo professor que pretende fazer da sua docência, principalmente no Ensino Superior, uma experiência que anuncie uma perspectiva crítica e emancipatória, a partir do currículo prescrito; e, por outro lado, uma realidade possível quando interpretamos a sala de aula como um espaço fundamental e necessário às relações pessoais e cognitivas em função do ensino e da aprendizagem que acontecem em uma via de mão dupla. Ou seja, professor e alunos, numa relação dia-lógica, ao mesmo tempo em que aprendem, também ensinam (FREIRE, 1996).

Essa compreensão do professor e alunos como sujeitos no processo de ensino e de aprendizagem nos faz pensar na possibilidade e, mesmo, na importância de envolver os alunos na construção do percurso curricular da disciplina Didática, no Curso Normal Superior, bem como nas decisões referentes às aulas desse componente curricular.

A princípio, trata-se de uma proposta instigante para o professor e para os alunos, uma vez que, no Ensino Superior, também estamos acostumados, por um lado, enquanto professores, a decidir o percurso a ser realizado, selecionar e ordenar o conteúdo julgado importante no currículo de formação, determinar quando e como se efetiva o processo de avalia- 
ção, entre outros procedimentos; desconsiderando o conhecimento, inclusive profissional, que o aluno traz consigo, antes mesmo de ingressar na Universidade, já que, no curso de formação inicial de professores, deparamo-nos, muitas vezes, com alunos que exercem a profissão de professor por serem habilitados no Magistério do Ensino Médio. Por outro lado, enquanto alunos, estamos habituados a esperar as propostas dos professores, a assistir às aulas, a cumprir o que foi determinado, enfim, a posicionarmo-nos passivamente, frente ao curso, à disciplina, ao conteúdo e à metodologia utilizada pelo professor.

Acreditando no espaço da possibilidade de um fazer pedagógico diferenciado a partir da concepção de currículo como construção de processos relacionais, intencionais e práticos, uma vez que "cada sujeito traz para dentro da sala de aula uma rede de saberes, construída em seus múltiplos espaços/tempos de experiência, e participa da rede tecida na sala de aula" (ALVES, 2002, p. 48) - que é o núcleo principal do currículo (PACHECO, 2000) -; acreditando, também, na necessidade da contextualização do currículo que traz, em si, dificuldades a serem enfrentadas, principalmente no que diz respeito ao ensino e à aprendizagem, e à reorientação das ações (KRAMER, 1997, p. 19); resolvemos nos lançar na experiência de construir, coletivamente, o currículo em sala de aula, na discipli- na de Didática, no quarto período do Curso Normal Superior, da Universidade do Vale do Paraíba - UNIVAP, em São José dos Campos, interior de São Paulo, no segundo semestre de 2004.

Sendo assim, o objetivo deste trabalho é analisar e refletir esse processo de construção do currículo em sala de aula, ou seja, o currículo em ação, identificando seus desafios e suas possibilidades no processo de formação inicial de professores, bem como no processo de formação contínua do professor de Ensino Superior que, ao mesmo tempo em que desempenha seu papel na formação de professores, trabalha em sua própria formação, principalmente porque acredita que "o processo de ensinagem se efetivará no trabalho em conjunto, na parceria de professores e alunos, numa nova aventura de ensinar e aprender na sala de aula da universidade. Além disso, a aventura e o compromisso da conquista do conhecimento solicitarão posicionamentos de sedução e parceria, na direção de um fazer solidário" (PIMENTA e ANASTASIOU, 2002, p. 218).

\section{ATRAJETÓRIA DA CONSTRU- ÇÃO DO CURRÍCULO DE DIDÁ- TICA EM SALA DE AULA}

\section{1 PERCURSO METODOLÓGICO}

O percurso metodológico para o desenvolvimento desse trabalho se 
insere na linha da "pesquisa participante", que visa à maior aproximação entre o pesquisador e o objeto ${ }^{1}$ de sua pesquisa.

Segundo Gajardo (1986, p. 44), a pesquisa participante, "em geral é utilizada para desenvolver práticas de pesquisa que incorporem os grupos excluídos das esferas de decisão à produção e comunicação de conhecimentos como às ações que disso possam derivar. Para tanto, ela combina técnicas de pesquisa, processos de ensino-aprendizagem e programas de ação educativa que [...] apontam para a promoção da produção coletiva de conhecimentos, rompendo o monopólio do saber e da informação, permitindo que ambos se transformem em patrimônio dos grupos marginalizados".

Assim, nessa proposta de investigar o processo de construção de currículo em sala de aula, podemos considerar, por um lado, os alunos como "grupo excluído", uma vez que, raramente, eles têm a possibilidade e oportunidade de participar das decisões em torno da efetivação do currículo na escola e em sala de aula.

Por outro lado, podemos considerar que as ações realizadas pelo professor e alunos do quarto período do Curso Normal Superior, na disciplina de Didática, sistematizada em sessenta horas, distribuídas em três horas/aula por semana, favoreceram um envolvimento dos sujeitos que resultou numa produção coletiva de conhecimentos, bem como essa experiência considerou as aspirações e potencialidades dos alunos e incentivou o desenvolvimento autônomo dos mesmos (Cf. BORBA, 1988).

Partimos de um exercício explora-tório com a intenção de diagnosticar a compreensão dos alunos a respeito de Didática, de currículo, de aula, de conteúdo, de planejamento; bem co-mo da definição de um contrato de trabalho pautado no compromisso de diálogo, participação e respeito, no sentido de desenvolvermos, durantes as aulas, uma abertura e acolhimento para que todos se sentissem à vontade para se expressarem e argumentarem suas interpretações, pois acreditamos em uma pesquisa que ultrapasse os aspectos acadêmicos e burocrá-ticos e que valorize o que as pessoas implicadas tenham a dizer e a fazer.

Organizamos diferentes ações que foram assumidas pelos participantes no decorrer de um semestre do curso, que serviram como instrumentos metodológicos para a coleta de dados no decorrer da pesquisa, a saber:

$>$ Definição de um aluno responsável, em cada aula, para desenvolver a observação e o registro. No início de cada aula, realizamos a leitura e a discussão das observações e do registro elaborado

${ }^{1} \mathrm{Na}$ perspectiva da pesquisa participante, o "objeto" é entendido como "sujeito", com potencialidades para reflexão e ação. 
pelo aluno. Esse material constituiu-se em um portfólio no decorrer do curso.

Discussão da pauta de atividade de cada aula e registro,no portfólio,dos registro momentos avaliativos no final de cada aula .

Instrumento de avaliação do professor e do aluno que foi discutido ao final de cada bloco de conteúdo trabalhado em sala, com a intenção de rever o percurso, melhorar a etapa subseqüente e trabalhar na perspectiva do comprometimento com a autoformação.

> Trabalhos individuais e aqueles desenvolvidos pelas equipes permanentes.

$>$ Realização de um encontro, definido como grupo focal (OLIVEIRA e FREITAS, 1998), no final da disciplina, em que os participantes manifestaram suas posturas e argumentaram os aspectos relevantes da experiência vivida na construção do currículo em sala de aula. Essa discussão, a partir da autorização dos participantes, foi gravada e transcrita.

De posse de todo o material coletado, privilegiamos, neste trabalho, os aspectos relacionados à organização do percurso curricular, ao transcurso das aulas, e ao processo de avaliação, como elementos fundamentais à compreensão da construção do currículo em sala de aula.

\subsection{A COMPREENSÃO DA SALA DE AULA: PROPONDO PARCE- RIAS NA ORGANIZAÇÃO DO PERCURSO CURRICULAR DA DISCIPLINA DIDÁTICA}

A compreensão da sala de aula, neste trabalho, ultrapassa a simples dimensão de um locus com espaço e tempo definido para a repetição e reprodução, em que se agrupa certo número de pessoas que se encontram na mesma etapa de formação, para atingir a dimensão de espaço e tempo de produção de conhecimentos válidos e necessários, em que se evidencia e se valoriza a multiplicidade e a complexidade de relações, exigindo, assim, a "incorporação das idéias de redes de conhecimento e de tessitura do conhecimento em rede, na compreensão de que estamos permanentemente imersos em redes de contatos diversos, diferentes e variados nas quais criamos conhecimentos e nas quais tecemos com os conhecimentos de outros seres humanos" (ALVES, 2002, p. 18).

Assumir a sala de aula como essa rede de conhecimentos que é tecida com a participação de todos, professor e alunos, exige a compreensão da necessária horizontalização do currículo. Ou seja, romper com a lógica do pensamento dominante que hierarquiza o conhecimento, para assumir a postura da não-linearidade, da nãosuperioridade de alguns saberes so- 
bre outros, bem como, o abandono das relações baseadas no poder de uns sobre os outros, fundamentando-se na valorização de cada pessoa e do seu saber que está em construção.

Iniciamos esse percurso a partir da seguinte questão: "O que eu entendo por Didática?”. As respostas assumiram dimensões variadas que organizamos em três blocos, por aproximação de idéias.

Em um primeiro bloco, alguns alunos demonstraram o desconhecimento do que vem a ser Didática e a existência de uma confusão do conceito com questões metodológicas de como ministrar uma aula.

No segundo bloco, os alunos apresentaram as seguintes respostas: "a maneira certa que o professor tem para ensinar; forma de desenvolver certas atividades; como fazer para trabalhar os conteúdos; etapas para elaborar um planejamento e os passos a serem seguidos em uma aula; forma de avaliar o aluno; recursos e instrumentos que os professores utilizam para o desenvolvimento de suas aulas".

É interessante perceber como essas expressões dos alunos manifestam uma concepção de Didática ainda pautada no senso comum, voltada, simplesmente, para um "fazer" que precisa atingir certo grau de sucesso. $\mathrm{Ou}$, ainda, enquanto instrumento externo que o professor pode lançar mão para desenvolver bem a sua aula.

Em um terceiro bloco, agrupamos as respostas dos alunos que entendem a Didática como uma competência desenvolvida pelo professor em sua profissionalidade. Os alunos desse grupo definem a Didática como: "Atitude que o professor tem na sala; conjunto de ações do professor; caminho que levará o professor a dominar os instrumentos de ensino que o auxiliarão no desenvolvimento de suas aulas".

Apresentamos, nesse momento, os objetivos da Didática na formação inicial dos professores, segundo as Diretrizes Curriculares Nacionais e o Projeto Pedagógico do Curso com o intuito de evidenciar aos alunos que, a partir desse currículo prescrito, os professores são responsáveis por desenvolvê-lo em sala de aula, escolhendo os conteúdos, definindo as metas e estratégias (SACRISTÁN, 2000, p. 166). Contudo, na tentativa de construir um currículo com indícios emancipatórios, esse percurso deve ser compartilhado com os alunos.

Para tanto, propusemos a seguinte questão: "Que saberes julgo necessários na minha formação em Didática?". Tal questão provocou um estranhamento por parte dos alunos. O exemplo de tal estranhamento é manifestado na seguinte fala:

Como podemos dar sugestões sobre o que queremos aprender? Não é o professor que deve apresentar o cronograma com o conteúdo a ser trabalhado? Eu acho que é a senhora (referindo-se à professora) que sabe o que é bom 
para a nossa formação. (Ana Paula)

Tal resposta nos evidencia o quanto, como alunos, somos impregnados dessa passividade frente ao currículo, e o quanto transferimos a responsabilidade da formação ao professor que, como autoridade, deve saber o que devemos ou não aprender, a ponto de sentirmo-nos despre-parados para opinar sobre "o quê" e o "como" aprender.

A dimensão do diálogo, entendido como encontro ontológico dos sujeitos mediatizados pelo mundo, ou ainda, "lugar de encontro, onde não há ignorantes absolutos, nem sábios absolutos: há homens que, em comunhão buscam ser mais" (FREIRE, 1987, p. 81), foi importante para fazer com que professor e alunos refletissem sobre as situações do cotidiano e se posicionassem sobre o que gostariam de estudar, uma vez que "a construção de um currículo crítico com sua busca da concreticidade encontra resposta na cotidianeidade do aluno, na cultura de que é portador" (SILVA, 1990, p. 17).

O exercício desse diálogo favoreceu o estabelecimento dos seguintes conteúdos a serem trabalhados no decorrer do curso: $\mathrm{O}$ conceito de Didática e o ensino como seu objeto de estudo; a sala de aula e a relação professor-aluno; a organização dos conteúdos; o planejamento da prática pedagógica e o processo de avaliação do ensino e da aprendizagem.

\subsection{O TRANSCURSO DASAULAS}

O transcurso das aulas de Didática foi marcado por algumas ações que fortalecem a convicção de que é possível construir um currículo em sala de aula, com indícios emancipatórios. Procuramos destacar, aqui, as questões mais apontadas pelos alunos nos registros das aulas e no grupo focal.

Em primeiro lugar, destacamos o tratamento didático do conteúdo marcado pelo diálogo enquanto "uma exigência existencial [...] que não pode reduzir-se a um ato de depositar idéias de um sujeito no outro, nem tampouco tornar-se simples troca de idéias a serem consumidas pelos permutantes. [...] É um ato de criação" (FREIRE, 1987, p. 79). Nesse sentido, a compreensão de que o conhecimento é um processo de criação, invia-biliza, completamente, a realização de aulas expositivas.

Dialogar sobre os conteúdos com os alunos assume, aqui, características problematizadoras no sentido de, por um lado, "criar espaço para um mútuo engajamento das diferenças vividas, que não exija o silenciar de uma multiplicidade de vozes por um único discurso dominante" (GIROX e SIMON, 2001, p. 106). E, efetivarse com um caráter autenticamente reflexivo, implicando, assim, um constante ato de desvelamento da realidade (FREIRE, 1987), de tentativa de passagem de um conhecimento baseado no senso comum para um conhe- 
cimento crítico, em que o referencial teórico utilizado assume o papel importante de detonador do diálogo, ponto de partida para buscas de outros referenciais teóricos, e de instigador para a compreensão da realidade educacional.

Assim, evidenciamos, em segundo lugar, as relações que os alunos estabelecem entre o que construímos nas aulas de Didática com suas práticas cotidianas desenvolvidas por eles nas escolas, enquanto professores e/ ou estagiários. Percebemos um avanço no sentido de que a observação e os relatos de suas experiências encaminham para a tentativa de ultrapassar a mera descrição ou opinião sobre a realidade, para atingir um estágio de interpretação da realidade, com um rigor criativo que provoca mudanças enquanto se conhece o objeto (FREIRE e SHOR, 1986). Assim evidenciou uma aluna:

Para mim as aulas de Didática eram sempre de reflexão sobre a prática de sala de aula, a teoria versus a prática. A professora problema-tizava muito, fazia a gente pensar de verdade, não era um conteúdo pronto. As aulas me permitiram analisar, confrontar e compreender o que eu estava vivenciando no estágio. (Mariana)

Em terceiro lugar, explicitamos a importância, nesse processo, do exercício do registro, definido como "documentos em que os professores anotam suas impressões sobre o que vai acontecendo em suas aulas" (ZABALZA, 2004, p. 13).

Articulado ao processo de reflexão sobre a prática, definido como uma "imersão consciente do homem no mundo da sua experiência" (GÓMEZ, 1997, p. 103), o registro apresentou-se como uma forma de materialização desse processo de imersão consciente do aluno, nas aulas de Didática, como aquele que observa, reflete e registra sobre aquilo que foi vivenciado. Essa postura contém ingredientes transformadores e modificadores da prática, uma vez que lida com a possibilidade do próprio aluno ser o sujeito na construção do currículo.

Finalmente, em quarto lugar, destacamos as dimensões da escuta e do respeito, como atitudes exercitadas, constantemente, em sala de aula, no acolhimento das construções realizadas pelos colegas, no confronto pessoal das formulações teórico-críticas, na certeza do enriquecimento pessoal com a contribuição e partilha dos colegas.

\subsection{O PROCESSO DE AVALIA- ÇÃO}

A avaliação, nessa experiência, foi caracterizada como um processo formativo, no sentido atribuído por Hadji (2001), de ser, antes de tudo, um processo informativo. Ou seja, aquela que "coloca à disposição do professor informações mais precisas, mais qualitativas, sobre os processos de 
aprendizagem, as atitudes e as aquisições dos alunos" (PERRENOUD, 1999, p. 149).

Além de oferecer subsídios ao professor, acreditamos que, na formação em nível superior, a informação que o próprio aluno constrói de si e do seu processo é de extrema importância, para a tomada de consciência da necessidade de assumir, cada vez mais, processos autônomos de autoavaliação que, no entender de Hadji, "é uma habilidade a construir [...] para permitir ao aluno que reflita, analise, construa progressivamente um modelo da tarefa que se tornará um referente adequado para fazer um exame crítico de sua produção, a fim de progredir rumo a um êxito maior" (HADJI, 2001, p. 103).

Para desenvolvermos essa prática de auto-avaliação, nessa experiência de construção do currículo em sala de aula, foi necessária a tentativa do rompimento com uma cultura de avaliação, em que a "prova oficial" (no final de cada bimestre) se mostra como o instrumento mais valorizado para expressar a construção de conheci- mento dos alunos - responsável pela aprovação ou reprovação dos mesmos - para assumirmos, coletivamente, a construção dialógica de critérios avaliativos no curso de Didática.

Procuramos esclarecer que, embora tenhamos a obrigatoriedade de uma avaliação pontual, solicitada pela Instituição, poderíamos fazer da avaliação um exercício de partilha de responsabilidades ao longo do processo, uma vez que, no decorrer do curso os alunos realizaram diversas ações e elaborações que exigiam sínteses teóricas do cotidiano da sala de aula.

As produções individuais e/ou coletivas dos alunos sempre iam acompanhadas com uma análise crítica, por escrito, para que o próprio aluno pudesse refletir sobre seu processo formativo, bem como a abertura de um espaço de discussão que chamávamos de devolutiva das atividades em que era possível destacar os ganhos, as dificuldades e as possibilidades de novos aprofundamentos.

Estabelecemos, também, critérios que serviram de parâmetros para o exercício da avaliação do professor, do aluno e do processo de ensino e de aprendizagem, no que diz respeito ao desempenho do aluno e do professor no transcurso das aulas. 


\begin{tabular}{|c|c|}
\hline \multicolumn{2}{|c|}{ CRITÉRIOS } \\
\hline Professor e Disciplina & Alunos \\
\hline $\begin{array}{l}\text { Favoreceu a construção de novos } \\
\text { conhecimentos. }\end{array}$ & $\begin{array}{l}\text { Participação, interesse e atenção nas } \\
\text { aulas }\end{array}$ \\
\hline Cumpriu o planejamento. & Freqüência às aulas \\
\hline As aulas relacionaram teoria à prática. & Realização de leituras prévias \\
\hline O professor foi mediador. & Realização de leituras independentes \\
\hline $\begin{array}{l}\text { Abriu caminhos para pensar no ato de } \\
\text { ensinar }\end{array}$ & $\begin{array}{l}\text { Comprometimento com as atividades e } \\
\text { com o grupo }\end{array}$ \\
\hline Favoreceu a compreensão dos assuntos. & Partilha de experiências \\
\hline As dúvidas foram esclarecidas. & $\begin{array}{l}\text { Acolhimento, respeito e escuta aos } \\
\text { colegas }\end{array}$ \\
\hline $\begin{array}{l}\text { Houve a oferta de novos materiais } \\
\text { (leituras...). }\end{array}$ & Levantamento de questões e dúvidas \\
\hline Favoreceu a partilha em sala de aula. & $\begin{array}{l}\text { Complementação das leituras com } \\
\text { outras }\end{array}$ \\
\hline Cumpriu o horário combinado. & Cumprimento do horário - pontualidade \\
\hline Freqüência do professor & $\begin{array}{l}\text { Responsabilidade (trabalhos, aulas, } \\
\text { conteúdos) }\end{array}$ \\
\hline
\end{tabular}

Ao final de cada unidade de conteúdo, realizamos a auto-avaliação, a partir desses critérios, com objetivo de rever, durante o processo, a trajetória percorrida e estabelecermos novas propostas de trabalhos que colaborassem com a evolução do aluno e do professor ao final de cada bimestre, alunos e professor traduziam os resultados das produções e do desempenho em uma nota.

Entendemos que essa auto-avaliação colaborou, intensamente, para o processo de auto-formação, uma vez que, sendo "participada e formadora (a auto-formação) considera a pessoa enquanto sujeito-objeto de sua própria formação, na percepção do movimento de construção e desconstrução de suas identidades e subjetivi- dades pessoais e profissionais no decorrer do seu ofício de mestre podendo contribuir para um agir consciente, responsável e comprometido" (MONTEIRO, 2002, p. 6).

\section{DESAFIOS E POSSIBILIDA- DES NA CONSTRUÇÃO DO CURRÍCULO EM SALA DE AULA}

Na trajetória dessa experiência de construção do currículo de Didática em sala de aula, foi possível nos depararmos, por um lado, com desafios, de diferentes ordens a serem enfrentados e, por outro lado, com possibilidades que contribuíram, imensamente, com a nossa prática pedagógica que tende a ter indícios de uma 
prática crítico-emancipatória.

Com relação aos desafios, em primeiro lugar, destacamos a dificuldade de encontrarmos espaços no currículo oficial para esse exercício. O que, só foi possível, pelo estabelecimento de parcerias com outro professor que trabalhava com essa mesma disciplina e com os alunos.

Em segundo lugar, os sessenta alunos que compuseram essa sala representam uma quantidade excessivamente grande, para o exercício dessa natureza, uma vez que, em muitos momentos, percebemos o comprometimento da qualidade do diálogo e da participação dos alunos, até mesmo em função do tempo destinado às aulas e à disciplina no currículo ofi-cial.

Atrelado a esse desafio, evidenciamos, em terceiro lugar, numa escolaridade marcada por uma cultura de transmissão de conteúdo, a tentativa de romper com a relação de poder que ainda sustenta, por um lado, o comportamento autoritário do professor e, por outro lado, a passividade do aluno. Contra esses comportamentos, identificados como elementos de um currículo oculto, a sistemática de diálogos constante fez-se necessária para a compreensão de que "o currículo crítico não se faz com uma inversão de posições, o professor cedendo o poder para o aluno, mas com uma atuação conjunta, porém, conduzida pelo professor" (SILVA, 1990, p. 53).

Em quarto lugar, o exercício da responsabilidade, da autonomia e do comprometimento com a própria for- mação, que "vai se constituindo na experiência de várias, inúmeras decisões, que vão sendo tomadas" (FREIRE, 1996, p. 120), demanda um amadurecimento dos alunos de graduação no sentido de compreender em que no nível superior embora ainda seja marcado pelo conteudismo e pela avaliação pontual, deve ser assumida por eles a dimensão da auto-formação.

No tocante às possibilidades emergidas nessa experiência da construção do currículo em sala de aula apontam os, em primeiro lugar, a tomada de consciência de que professor e alunos são sujeitos do processo. $\mathrm{E}$, como tal, com direito à participação de sua construção. O que torna, para o professor, o trabalho mais leve.

Em segundo lugar, a compreensão da sala de aula como um espaço fundamental e necessário às relações pessoais e cognitivas em função do ensino e da aprendizagem, altera, essencialmente, o exercício dos papéis de professor e aluno, que deixa de ser uma relação unidirecional (professor $\rightarrow$ aluno), caracterizada pela detenção e transmissão de um determinado conteúdo, para assumir características de uma relação de mão dupla (professor $\Leftrightarrow$ aluno), caracterizada pela construção coletiva do conhecimento; embora seja muito clara a responsabilidade que o professor tem de conduzir e mediar o processo.

Em terceiro lugar, a constatação de que o exercício da horizontalização do currículo, ou seja, sua construção 
com a participação efetiva dos alunos, não ameaça, em hipótese nenhuma, a qualidade do trabalho a ser desenvolvido. Muito pelo contrário, o envolvimento dos alunos no processo resultou um maior comprometimento com sua própria formação.

$\mathrm{E}$, finalmente, em quarto lugar, apontamos a constatação da possibilidade de experienciar, no nível superior, um currículo que traz, em si, indícios emancipatórios, percebido, por um lado, no movimento de açãoreflexão-ação, considerado como mola mestra de uma prática emancipatória (SAUL, 2000), favorecendo a reflexão crítica sobre os conteúdos, sobre as aulas, sobre a formação que favoreceu, certamente, ações transforma-tivas na realidade educacional em que os alunos atuam.

Por outro lado, o envolvimento intenso e efetivo de professor e alunos nesse processo de construção democrática do currículo, demonstra que nessa experiência foi possível democratizar a relação de poder que se estabelece, ocultamente, entre professor e aluno e vivenciar a relação dialógica educador - educando, na certeza de "o educador já não é o que apenas educa, mas o que, enquanto educa, é educado, em diálogo com o educando que, ao ser educado, também educa" (FREIRE, 1987, p. 68).

\section{REFERÊNCIAS}

ALVES, N. (Org.). Criar currículo no cotidiano. São Paulo: Cortez, 2002. (Sé- rie Cultura, Memória e Currículo, 1)

BORDA, O. F. Aspectos teóricos da pesquisa participante: considerações sobre o significado e o papel da ciência na participação popular. IN: BRANDÃO, C. R. (Org.). Pesquisa participante. 7. ed. São Paulo: Brasiliense, 1988.

FREIRE, P. Pedagogia do oprimido. 17. ed. Rio de Janeiro: Paz e Terra, 1987.

Pedagogia da autonomia. São Paulo: Paz e Terra, 1997.

FREIRE, P.; SHOR, I. Medo e ousadia: o cotidiano do professor. 8. ed. Rio de Janeiro: Paz e Terra, 2000.

GAJARDO, M. Pesquisa participante na América Latina. São Paulo: Brasiliense, 1986.

GIROUX, H.; SIMON, R. Cultura popular e pedagogia crítica: a vida cotidiana como base para o conhecimento curricular. In: MOREIRA, A. F.; SILVA, T. T. (Orgs.). Currículo, cultura e sociedade. 5. ed. São Paulo: Cortez, 2001.

GÓMEZ, A. P. O pensamento prático do professor: a formação do professor como profissional reflexivo. In: NÒVOA, A. (Org.). Os professores e a sua formação. 3. ed. Lisboa: Publicações Dom Quixote, 1997.

HADJI, C. Avaliação desmistificada. Porto Alegre: Artmed, 2001.

KRAMER, S. Propostas pedagógicas ou curriculares: subsídios para uma leitura crítica. Educação \& Sociedade, Campinas, v. 28, n. 60, p. 15-35, dez. 1997.

MONTEIRO, A. L. Autoformação, histórias de vida e construções de identidades do/a educador/a. Tese (Doutorado) - Pontifícia Universidade Católica de São Paulo, São Paulo, 2002. 
OLIVEIRA, M.; FREITAS, H. A realidade operacional do FOCUS GROUP como investigação qualitativa: feedback de uma experiência monitorada. In: ENANPAD/ ANPAD, 22, Anais... Foz do Iguaçu, 1998.

PACHECO, J. A. Políticas curriculares descentralizadas: autonomia ou recentralização? Educação \& Sociedade, Campinas, v. 21, n. 73, p. 139-161, 2000.

PERRENOUD, P. Avaliação: da excelência à regulação das aprendizagens. Porto Alegre: Artmed, 1999.

PIMENTA, S. G.; ANASTASIOU, L. G. C. Docência no ensino superior. São Paulo: Cortez, 2002. (Coleção Docência em Formação, 1)

SACRISTÁN, J. G. O currículo: uma reflexão sobre a prática. 3. ed. Porto Alegre: Artmed, 2000.

SAUL, A. M. Avaliação emancipatória. 5. ed. São Paulo: Cortez, 2000.

SILVA, T. M. N. A construção do currículo na sala de aula: o professor como pesquisador. São Paulo: EPU, 1990.

ZABALZA, M. A. Diários de aula: um instrumento de pesquisa e desenvolvimento profissional. Porto Alegre: Artmed, 2004.

Enviado em: 17/04/06

Aceito em: 14/08/06 